\title{
E-Assessment, Inequity and Accountability in the New Normal Era and Beyond in Nigerian Universities
}

\author{
Abdul-Wahab Ibrahim*, Abdullahi lliyasu \\ Department of Education, Sule Lamido University, P.M.B. 048, Nigeria \\ *Correspondence: abdulwahab.ibrahim@slu.edu.ng
}

Received: 28 November 2021; Accepted: 16 December 2021; Published: 27 December 2021

\begin{abstract}
The study examined the perceived conduct of e-assessment of undergraduate courses in Nigerian universities and compared access to e-assessment among undergraduate students in universities in the country. It also determined the relationship between e-assessment-based accountability and test fairness in the conduct of e-assessment in Nigerian universities. These were with a view to improving the assessment outcome directed towards certifying the quality in education by the Nigerian universities. The study adopted a mixed research approach combining both descriptive survey and focus group designs. The population consisted of all undergraduate students who registered for their degree courses at the government and privately-owned universities during 2019/2020 academic session. The sample consisted of intact classes of 450 Parts 2, 3, and 4 undergraduate students who registered for their degree courses. A 32-item self-developed instrument was used in the study. The qualitative data was collected via focus group. Data were analysed using independent t-test, and Pearson Product Moment Correlation statistical methods. The results showed that there existed a significant difference in students' perception of the conduct of e-assessment in Nigerian universities. Also, there was a significant difference in access to e-assessment among undergraduate students in the universities. Further, a significant relationship existed between e-assessment-based accountability and test fairness in the conduct of e-assessment in Nigerian universities. The study concluded that improper conduct of e-assessment forms a major threat to the fairness and validity of online assessment of students. It was recommended that universities' Management should employ equitable strategies in the design, development and administration of the e-assessment on campuses in the country.
\end{abstract}

Keywords: new normal, e-assessment, inequity, accountability, fairness

\section{INTRODUCTION}

The educational crisis caused by the sudden emergent of Coronavirus Disease -19 (COVID-19) more than a year ago is yet to be abated throughout the world. In Nigeria and as it is the case in major parts of the world, with the spread of the COVID-19 pandemic, most of the world's universities have had to close campuses and send their students home. Thus, the outbreak of the COVID-19 pandemic and the subsequent lockdown has necessitated a rapid move to e-learning culminating in the adoption of e-assessment in the universities (Ibrahim, 2021; Ibrahim \& Hudu, 2020).

The imperative and advanced use of Information Communication Technology (ICT) in every aspect of daily life has become the norm in both public and privately-owned Universities in Nigeria. For instance, ICT apps/media, especially WhatsApp, Zoom, Google Meet, Webinar, and Telegram, are some of the most veritable platforms used for academic purposes, serving both audio and audiovisual communications. Indeed, these media have been adopted in Universities in the country since the outbreak of COVID-19 pandemic. Put differently, Nigerian Universities have swiftly adopted virtual/online learning, fully integrating their students into an academic process that ensures that the impact of COVID-19 has not been able to stunt the academic progress of their students, thereby delaying them at all (Ibrahim, 2021). 
However, a major problem is how to examine students in the midst of coronavirus outbreak and lockdown. Written assignments can be done online, as well as theses, including their presentations and defenses. But in the case of examinations, the most common form of assessment, in particular at the undergraduate level and for large cohorts, there are concerns about assessment inequity, and accountability. There are serious assessment inequity concerns about the use of algorithms by Google, Facebook, and Zoom in invigilating examinations and conduct e-assessment, hence the need to examine the conduct of e-assessment of undergraduate courses in Nigerian universities and compared access to e-assessment among undergraduate students in universities in the country. Similarly, Winkley (2010) observed that assessment equity is about fairness and social justice and the acknowledgement of differences. It references the differential or unequal distribution of resources or inputs for the purpose of meeting a specific need to address a particular purpose or outcome.

Against this backdrop, assessment sits at the heart of the learning process, as it provides observable evidence of learning, determines student progress and demonstrates understanding of the curriculum. More broadly, it could be said that an institution, culture, or society depicts its conceptualisation of learning and ideal future citizens by how it creates and uses assessment. Assessment as a concept embraces a wide range of approaches used to measure educational effectiveness. Simply put, assessment reveals what a student understands, knows and can do. Assessment is not an alternative to learning, but to support learning (Ibrahim, 2021; lbrahim, 2019).

Conceptually, e-assessment means application of ICT in the assessment process, from presentation of questions to the saving of the learners' responses. This means that the design, test implementation, marking, recording the responses and providing feedback are all done by using ICT. As Okoroafor (2020) asserts "with e-assessment learning processes are developed, and students are able to obtain immediate and direct feedback" (p.3). Thus, e-assessment involves the use of ICT in the assessment process, as it energises and reinforces the students by encouraging them to perform better since it works on their motivation. Accordingly, if assessment is the yardstick for placement of students, there is need to make it fair, to provide true, adequate and equitable assessment for all students. The reverse is the case nowadays. For instance, there have been occasions when undergraduate students complain after the conduct of e-assessment by the universities that the assessment was unfair because they do not enjoy equal access to e-assessment devices that are used in conducting such e-assessment. According to Okoroafor (2021), fair assessment is the assessment in which students are given equitable opportunities to demonstrate what they know, and should serve the interests of individual student, the school and wider society.

Equitability in the sense that students are assessed using methods and procedures most appropriate to them. Likewise, United Nations Educational, Scientific and Cultural Organization (UNESCO) (2020) conceptualised fair assessment as the assessment that considers the learners' needs and characteristics, and any reasonable adjustments that need to be applied to take account of them. That means for assessment to be fair, the learner must be adequately informed and is able to participate in the assessment process, and agrees that the process is appropriate, since fair and equity is a concern for educators, students and parents. A fair assessment should not discriminate between learners, except on the grounds of the ability being assessed, especially in the high-stakes examinations like university examinations, which are expected to be standardized. Further, e-assessment inequity is compounded and broadened with the "exacerbated inequities brought on by disruptions in normal school due to the COVID-19 pandemic" (National Academy of Education (NAEd), 2021, p.5). Thus, assessment and accountability systems play an important role in advancing educational equity, hence the need to implement equitable e-assessment in Nigerian universities. According to NAEd (2021), fair assessments are sensitive to the characteristics of different groups being assessed and thereby, where appropriate, employ equitable strategies in the design, development, and delivery of the assessment results. Without a doubt, test fairness is a crucial issue in e-assessment because one of the important factors, which should be considered in ensuring the validity of any test, is the issue of fairness and equity (Ibrahim, 2018). As a corollary to the above, this study investigates the perceived conduct of e-assessment, access to e-assessment amongst undergraduates and the relationship 
between e-assessment-based accountability and test fairness in the conduct of e-assessment in Nigerian universities.

The main objective of this study is to investigate the nature of the conduct of and access to e-assessment of undergraduate courses in Nigerian universities. Thus, the specific objectives of the study are to: (1) Examine whether difference exists in students' perception of the conduct of eassessment in Nigerian universities; (2) Compared if difference exists in access to e-assessment among undergraduate students in universities in the country; and (3) Determined whether relationship exists between e-assessment-based accountability and test fairness in the conduct of e-assessment in Nigerian universities.

Based on the objectives of this study, the following research hypotheses were postulated to provide further guide to the study: (1) There is a significant difference in students' perception of the conduct of e-assessment in Nigerian universities; (2) There is a significant difference in access to eassessment among undergraduate students in the Nigerian universities; (3) There is a significant relationship between e-assessment-based accountability and test fairness in the conduct of eassessment in Nigerian universities.

\section{METHOD \\ Research Design}

This study is an exploratory study adopting a mixed research approach combining both survey and focus group research designs. A survey research design allows for the collection of quantifiable data from a sample to explain a particular phenomenon (Upadhya and Singh, 2008). The focus group can highlight the diversity of perspectives and discovers underlying attitudes, but Anderson and Arsenault (1998) remind us that focus groups must have a clear idea of purpose and must be skillfully planned and facilitated. In this case the purpose is to provide more depth and breadth to the data collected in order to develop a broad analytical framework through which the investigation of conduct of e-assessment could be better understood; and to also extract undergraduate students' perception of the conduct of e-assessment as organised and implemented by the universities in Nigeria, their past experiences and viewpoints, their preferences and the problems they confronted in accessing e-assessment.

\section{Participants}

All undergraduate students who registered for their various degree courses in the public and privately-owned universities in both Kano and Jigawa States of the Nigerian federation constituted the target population for the study. However, the accessible population of the study comprised of 200 Level and above undergraduate students who registered for their different degree courses during $2019 / 2020$ academic session in the two government owned universities and a privately-owned university in both Kano and Jigawa States in Nigeria. From the sample list obtained from the three universities, there are a total of 10,000 200 Level and above undergraduate students respectively who registered for their different degree courses during 2019/2020 academic session. It was from this accessible population of the study that 450 students were sampled using accidental and snowball sampling procedures simultaneously. Since the study focused on the conduct of e-assessment, undergraduate students in 200 Level and above were used as participants because they were considered to have stayed long enough in the university environment and therefore would be able to give meaningful response for the study. Noteworthy, owing to social distancing rules operating in Nigerian universities including the three universities selected for the study, both accidental and snowball sampling techniques were used to select the sample for the study. On accidental meeting of students on campus, participants were motivated to participate in the study and were asked to kindly share the photocopies of the research instrument with their colleagues on campus as well as through their e-mail contacts. These methods ran concurrently for three weeks; hence 450 undergraduate students successfully completed the instrument.

\section{Research Instrument}


A 32-item self-developed instrument was used in the study namely: "Perception and Access to e-Assessment Questionnaire (PAAQ)", and viva-voce interview. The PAAQ was used to collect data for the study. It consists of two parts, A and B which consists of 32 items as its construction relied heavily on literature review. The qualitative data was collected via focus groups. Upadhya and Singh (2008) pointed out that if the researcher is genuinely concerned with exploring the views and experiences of the participants in the study then the mechanisms he/she uses must allow for this and encourage it. Therefore, the use of focus groups, in addition to the questionnaires, was deemed appropriate. To qualify for the interview, only participants that show willingness and readiness were incorporated into the interview session for the study. The interview was led by the researchers, assisted by two research assistants who took notes and tape recorded the conversation over time.

The content and construct validity of PAAQ was established using expert judgment from experts in Tests and Measurement, Statistics, and Educational Psychology. They were given the instrument for scrutiny and modification to establish the content validity of the instrument. The experts were able $t$ review the items in the instrument in terms of relevance to the subject-matter, coverage of the content areas, appropriateness of the language usage, and clarity of purpose. The experts' judgments revealed that the instrument had adequate content, construct and face validity. Thereafter, a reliability test was conducted by administering the instrument on 20 respondents, who were not participants in the study but were students in a sister university in one of the two states used for the study. Their responses were analysed to determine Cronbach's Alpha and internal consistency reliabilities. The Cronbach's Alpha coefficient obtained was 0.89 , indicating a high internal consistency. Also, Spearman Brown Split-half reliability coefficient was 0.87. These coefficient values were acceptable as appropriately high for study of human behaviour due to its complexity. Consequently, the instrument was accepted as being stable across items, hence its usage in this study.

\section{Procedure for Data Collection}

The instrument was administered by the researchers. The hard copies of the instrument were administered on the students with the assistance of the trained research assistants who are at the same time Graduate Assistants in the selected three universities for the study. Since a combination of accidental and snowball sampling techniques was used to make sure a substantial sample of students participated in the study, a handful of undergraduate students served as informants to their colleagues about the study and took the responsibility to send the copies of the questionnaire to their colleagues and retrieve the same on the spot assessment. This was possible through the assistance of Graduate Assistants in these universities who coordinated the whole process due to their familiarity with some of the students.

Furthermore, the participants were instructed not to omit any item as it is mandatory to respond to all items in the questionnaire. Such a procedure provided a uniform response set thereby minimizing individual differences in responding. The administered instrument copies were collected immediately. A total of 450 copies of the instrument were administered, while 435 copies were finally collected on return, as being properly completed and were used for analysis.

\section{Method of Data Analysis}

The data obtained for this study to test the hypotheses were analysed with the use of independent t-test, and Pearson Product Moment Correlation statistical methods using updated SPSS version 21.0. All hypotheses were tested at 0.05 level of significance.

\section{RESULT AND DISCUSSION}

To interpret the viva-voce interview with the focus group, content analysis was carried out on each of the items for discussion, following the procedure by Creswell and Creswell (2018). The data were edited and pieced together theme-by-theme, to ensure accuracy and authenticity of the participants' responses. This procedure ensures a first-hand account of the issues responded to by participants in the interview. 


\section{On Students' Perception}

When the online examinations were conducted in the students' respective universities, some students were disappointed because of hitches encountered, while some were satisfied with the conduct, but called for an improvement. Some of the issues were poor network connection, being logged out during the examinations, and inability to log in to continue, among others. Those who could not log in to continue had their examinations rescheduled. A 300-Level student of Human Kinetics Education said: "The conduct of the examination generally was fair on my path. I cannot really say the examination was a success or a failure. I hope for a better conduct next time and improvement in subsequent exams."

Another student, a 200-Level student stated: "The examination was nearly itch-free; there is room for improvement. I can say the examination was a $90 \%$ success, as there were minimal complaints; 5 per cent of the glitch can be traced to the students, not the site, not all the students are computer literate. I could not type on the chat box; they needed to resolve that. The questions per page should be more than one, at least, three questions; this will save a handful of data."

Likewise, another 200-Level student of Electrical Electronics, presented a bitter experience when she expressed that the online examinations should be discontinued. She noted that the time allotted for the examinations was not enough. She stated: "I do not think the online examinations should be continued. The time allocated for the courses was not enough for me. All the courses had a time limit of one hour or less. There were log in issues also as a result of network errors."

However, another a 300-Level student of English, does not want online examinations scrapped. He urged authorities in the institution to work on improving the server. He said: "The online class has come to stay and improving it is better than scrapping it. The area I seek improvement is the server. However, with what I know, all the hitches occurred because of poor network. However, the university should just hold occasional seminars enlighten students on the workings of the computer system."

Further, a 300-Level student of the Department of Science and Technology Education, wants the examinations cancelled because of high cost of data. He added that the examinations went well for him. "Though the examination went well for me, I do not think it should be continued subsequently. This is as a result of high cost of data in online learning and testing. Then, we have no idea of the new courses that we would be registering next. It is tough when students bear the cost of data," he said.

\section{On Students' Access to e-Assessment}

A 200-Level student of the Department of Psychology, complained of being logged out during the examination. He added that his examination had been rescheduled because of the hitch. He stated: "I was logged o ut during the examination and could not log in till the end of the examination. I already complained and they promised to look into it. It has been rescheduled for another day. I cannot really grade the general success of the examinations now. When results are out, I would be able to do that. However, the concept of online testing is nice."

Similarly, a 200-Level student, stated: "I missed two examinations; I was logged out due to bad network. I hope they improve for a better conduct of the examination next time. The ways they can improve include getting good web developers for the site, provision of enough data for students and provision of materials such as laptops."

Further, a 400-Level student stated that the conduct of the examination was fair. She, however, hopes the school improves by providing access to gadgets like laptops and internet connection. She stated: "I think the conduct of the exam was fair, although I never experienced network difficulty but some of my colleagues complained about it. If there should be any improvement, I think it should be in the area of accessing laptops or desktops as well as internet connection by the school authority. The public are aware of the private universities in the country but opt for public ones for different reasons. Besides private universities do not have access to 
government grants and other benefits unlike the public universities. That should make public universities capable of providing what is needed," she said.

Again, a 200-Level student of Business Administration, stated: "There were lots of lapses encountered by students like network issues, server not loading the questions, time factor, among others. Nevertheless, management should look into all the issues because somehow some students have been psychologically affected."

A 200-level student of English Education said the examination was not really bad, but there were issues concerning the setting of the questions, connection issues and the time frame. She said: "The online examination was not that bad, just the challenge of network connections and other issues. Also, the way the questions are set are not okay; a question per page, it causes tension before it leads to another page, consuming students' time and data. They could have also given students enough time to work. We hope they improve next time."

\section{Hypotheses Testing and Interpretation of Results}

Table 1. Difference in Students' Perception of the Conduct of e-Assessment in Nigerian Universities

\begin{tabular}{lccccccc}
\hline Students' Perception & $\mathrm{N}$ & Mean $(\bar{x})$ & SD & MD & DF & t-cal & t-critical \\
\hline High Perception & 166 & 22.17 & 3.63 & 1.61 & 433 & $4.032^{*}$ & 1.648 \\
Low Perception & 269 & 20.56 & 4.09 & & & & \\
\hline "Significant; $d f=433 ; p<0.05$ & & & & & &
\end{tabular}

Table 1 indicated that the calculated t-value of 4.032 is greater than the critical $t$-value of 1.648 given 433 degree of freedom at 0.05 level of significance. Consequently, the research hypothesis was confirmed. This implies that there is a significant difference in students' perception of the conduct of e-assessment in Nigerian universities.

Table 2. Difference in Access to e-Assessment among Undergraduate Students in Nigerian Universities

\begin{tabular}{llllllll}
\hline Students' Access & N & Mean $(\bar{x})$ & SD & MD & DF & t-cal & t-critical \\
\hline Public University & 287 & 18.13 & 2.36 & 0.21 & 433 & $2.701 *$ & 1.648 \\
Private University & 148 & 17.92 & 3.15 & & & & \\
\hline
\end{tabular}

"Significant; $d f=433 ; p<0.05$

Table 2 showed that the calculated t-value of 2.701 is greater than the critical t-value of 1.648 given 433 degree of freedom at 0.05 level of significance. Consequently, the research hypothesis was retained. This implies that there is a significant difference in access to e-assessment among undergraduate students in the Nigerian universities.

Table 3. Relationship between e-Assessment-Based Accountability and Test Fairness in the Conduct of e-Assessment in Nigerian Universities

\begin{tabular}{lllllllr}
\hline Variables & N & Mean $(\bar{x})$ & SD & MD & DF & r-cal & r-critical \\
\hline Accountability & 435 & 16.53 & 1.79 & 0.22 & 433 & 0.483 & 0.088 \\
Test Fairness & 435 & 16.31 & 2.16 & & & & \\
\hline
\end{tabular}

"Significant; $d f=433 ; p<0.05$

Table 3 revealed that the calculated $r$-value of 0.483 is greater than the critical $r$-value of 0.088 given 433 degree of freedom at 0.05 level of significance. Consequently, the research hypothesis was confirmed. This implies that there is a significant relationship between e-assessmentbased accountability and test fairness in the conduct of e-assessment in Nigerian universities 


\section{Discussion}

The purpose of this study was to investigate the perceived conduct of and access to eassessment of undergraduate courses in Nigerian universities. Thus, the finding in hypothesis one revealed that there is a significant difference in students' perception of the conduct of e-assessment in Nigerian universities. This implies that difference exists in the way students' perceived the conduct of e-assessment in universities in Nigeria. Basically then, this finding is in line with Ibrahim and Saleh (2020) confirmation that perception of students can influence what they learn and how they learn and internalize it. Thus, what is seen or heard will depend on what one already knows and how he reacts. Therefore, each individual student's perception of reality determines his behaviour (Ibrahim, 2014).

Further, the finding is in consonance with the earlier theories (Schachter, 2008; Evertson, 2001). Specifically, Evertson (2001) in set and motor adjustment theory asserted that individuals perceive one thing at a time and as such, when a number of things or objects are seen, a clear perceptual act requires some organisation to produce a kind of unity. Also, Schachter (2008) in sensory-tonic field theory claimed that perception is a total dynamic process in which the sensory (i.e., ear, eye, and other movement) and tonic (part or whole body movements) factors combine to have a common dynamic outcome. Basically then, this suggests the divergence in student's perception of the conduct of e-assessment of undergraduate courses in Nigerian universities. For instance, as it was found in the context of this study, when e-examinations were conducted in the students' respective universities, partly, some students were disappointed because of hitches encountered, while some were satisfied with the conduct, culminating in the confirmation of the research hypothesis which stated that a significant difference existed in students' perception of the conduct of e-assessment in Nigerian universities.

The finding for hypothesis two revealed that there is a significant difference in access to eassessment among undergraduate students in the Nigerian universities. The foregoing result confirmed previous studies (Ibrahim, 2021; Ibrahim \& Hudu, 2020), which reported a statistically significant relationship between the socioeconomic status and the digital divide in accessing remote learning; significant differences in students' access to remote learning opportunities during the pandemic, and significant differences in access to digital tools between students in government schools and their private school counterparts.

For instance, the view of a final-year (400 Level) undergraduate student in one of the selected Universities in the study corroborated the finding on a significant difference in access to eassessment among undergraduate students in the Nigerian universities, when quipped that:

"I am not comfortable with the entire e-learning and assessment programme. Even if you have the money, to get good internet reception is a problem. Sometimes you may be in your room and the entire environment may not have internet service, and you may have a class at that exact time and it won't be possible to attend. So, if you are given a particular hour to write an exam paper and there is no network, how will the person meet the exact timing of the school? If it was in a very technologically advanced country, like America, it could be acceptable, but this is Nigeria. And once you cannot guarantee equal access for all the students - some in Kano, some outside Lagos, some in their villages - then really it will not be ideal to have anything like that. Unfortunately, we cannot guarantee digital devices (internet) access in Nigeria."

Therefore, internet services are patchy across the country (Nigeria) and the problem has been exacerbated by poor socio-economic background of the majority of individual students, preventing students from having digital access to e-assessment as at when due dovetailing into some students crossing state borders in order to base themselves in areas with well-developed internet services. It is no wonder that students present a litany of stumbling blocks such as epileptic power supply, erratic internet network, and limited access and penetration of the internet; universities being ill-equipped for online education because of lack of infrastructure for the purpose, and the poverty level of many 
students. It is believed, and for good reasons, that most students in publicly-owned universities cannot afford a laptop, a smartphone, or a table.

The finding for hypotheses three indicated that there is a significant relationship between eassessment-based accountability and test fairness in the conduct of e-assessment in Nigerian universities. This finding is consistent with the confirmations of Okoroafor (2021); NAEd, (2021); and UNESCO (2020), which stated that fair assessment is the assessment in which students are given equitable opportunities to demonstrate what they know, and should serve the interests of individual student, the school and wider society. Particularly, the finding corroborates NAEd (2021) postulation that fair assessments are sensitive to the characteristics of different groups being assessed and thereby, where appropriate, employ equitable strategies in the design, development, and delivery of the assessment results. Hence, assessment and accountability systems play an important role in advancing educational equity, hence the need to implement equitable e-assessment in Nigerian universities.

Thus, equitability in the sense that students are assessed using methods and procedures most appropriate to them. A fair assessment should not discriminate between learners, except on the grounds of the ability being assessed, especially in the high-stakes examinations like university examinations, which are expected to be standardized. According to lbrahim (2018), test fairness is a crucial issue in e-assessment because one of the important factors, which should be considered in ensuring the validity of any test, is the issue of fairness and equity.

\section{CONCLUSION}

Based on the findings obtained from the study, it can be concluded, therefore, that a significant difference existed in students' perception of the conduct of e-assessment and access to eassessment among undergraduate students in the Nigerian universities. Also, there existed a significant relationship between e-assessment-based accountability and test fairness in the conduct of eassessment in Nigerian universities.

\section{RECOMMENDATIONS}

From the findings above, the following are recommended as follows:

1. To ensure that COVID-19 and its attendant lockdown does not stunt the academic activities in the Universities, e-assessment should be made efficient and strengthened in Nigerian universities.

2. That universities' Managements should employ equitable strategies in the design, development and administration of e-assessment on campuses in the country.

3. For e-assessment to be sustainable, provision should be made on how the less privileged can get access to the use of a computer and afford the expenses involved particularly in data accessibility.

4. Universities would have to train their support service staff and equip them with communication skills to deal with the peculiarities of the demands in the online school assessment.

\section{REFERENCES}

Anderson, G., \& Arsenault, N. (1998). Qualitative research. Fundamentals of educational research, 2, 119-135.

Creswell, J. W., \& Creswell, J. D. (2018). Research Design: Quantitative, qualitative and mixed methods approaches. Sage Publications, Inc.

Evertson, C. M. (2001). Relationship between classroom behaviour and student outcome in junior high school mathematics and English language. American Educational Research Journal, 17(1), 43-60.

Ibrahim, A. (2021). Investigating educational significance of e-learning in Nigerian universities postCOVID-19: Implications for assuring quality e-assessment. E-Journal of Education, 9, 207218. 
Ibrahim, A., \& Hudu, S. (2020). COVID-19 pandemic: The exigency of e-learning and challenges in Nigerian public and privately-owned primary and secondary schools. In A. O. Ekong, S. M. Usen, \& E. N. Essien (Eds.), Developing alternative teaching: Continuity plans to move classrooms online at Covid-19 era in Nigeria (pp.217-227). Benchmark Educational Services.

Ibrahim, A., \& Saleh, B.A. (2020). Schooling process: Is schooling experience and its outcome the same for girls and boys? Randwick International of Education and Linguistics Science (RISS) Journal, 1(2), 126-139. https://doi.org/10.47175/rielsj.vli2.80

Ibrahim, A. (2019). Scaling up assessment for learning implementation in tertiary institutions for sustainable national development. Premier Journal of Education, 2(1), 1-18. www.benchmarkjournals.com

Ibrahim, A. (2018). Improving assessment and evaluation skills of public-school teachers in Jigawa State. Journal of Education and Practice, 9(11), 22-32. www.iiste.org

Ibrahim, A. (2014). The students' perception of teachers' classroom effectiveness on their selfconcepts in Lagos metropolis. Journal of Teaching and Teacher Education, 2(2), 133141. http://journals.uob.edu.bh

National Academy of Education (NAEd) (2021). Educational assessments in the COVID-19 era and beyond. NAEd. Forum Series. naeducation.org

Okoroafor, B. O. (2021). Ensuring fair assessment practices: Implications for high-stakes examination. Jigawa Journal of Multidisciplinary Studies, 4(1), 78-91.

Okoroafor, B.O. (2020). E-Assessment, uses and implementation challenges in higher institutions in Nigeria. Jigawa Journal of Multidisciplinary Studies, 3(2), 1-11.

Schachter, S. (2008). Cognitive effects of bodily functioning. In K. Doyle Jr. (Eds.), Interaction: Readings in human psychology (pp. 145-148). D.C. Health and company.

Upadhya, B., \& Singh, Y.K. (2008). Advanced educational psychology. APH Publishing Corporation.

United Nations Educational, Scientific and Cultural Organization (UNESCO), (2020). COVID-19 education response: How many students are at risk of not returning to school? Advocacy Paper, 6-8.

Winkley, J. (2010). E-assessment and innovation. emergingtechnologies.becta.org.uk

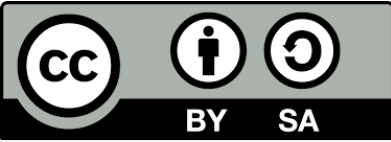

Copyright (c) 2021 by the authors. This work is licensed under a Creative Commons Attribution-ShareAlike 4.0 International License. 